\title{
Enhancement of Bone Regeneration on Calcium-Phosphate-Coated Magnesium Mesh: Using the Rat Calvarial Model
}

OPEN ACCESS

Edited by:

Chaozong Liu,

University College London,

United Kingdom

Reviewed by:

Sergey V. Dorozhkin,

Independent Researcher, Moscow,

Russia

Jennifer Patterson,

Instituto IMDEA Materiales, Spain

Yu-Lung Chiu,

University of Birmingham,

United Kingdom

${ }^{*}$ Correspondence:

Yong-Seok Jang

yjang@jbnu.ac.kr

Min-Ho Lee

mh@jbnu.ac.k

tThese authors have contributed equally to this work and share last authorship

Specialty section:

This article was submitted to Biomaterials,

a section of the journal Frontiers in Bioengineering and

Biotechnology

Received: 12 January 2021 Accepted: 22 March 2021

Published: 29 April 2021

Citation:

Wu S, Jang Y-S and Lee M-H (2021) Enhancement of Bone

Regeneration on

Calcium-Phosphate-Coated Magnesium Mesh: Using the Rat

Calvarial Model.

Front. Bioeng. Biotechnol. 9:652334.

doi: 10.3389/fbioe.2021.652334

\begin{abstract}
Shuang Wu, Yong-Seok Jang*t and Min-Ho Lee*†
Department of Dental Biomaterials, Institute of Oral Bioscience, Institute of Biodegradable Material, School of Dentistry, Jeonbuk National University, Jeonju-si, South Korea
\end{abstract}

Metallic biodegradable magnesium (Mg) is a promising material in the biomedical field owing to its excellent biocompatibility, bioabsorbability, and biomechanical characteristics. Calcium phosphates (CaPs) were coated on the surface of pure $\mathrm{Mg}$ through a simple alkali-hydrothermal treatment. The surface properties of CaP coatings formed on Mg were identified through wettability, direct cell seeding, and release tests since the surface properties of biomaterials can affect the reaction of the host tissue. The effect of $\mathrm{CaP}$-coated $\mathrm{Mg}$ mesh on guided bone regeneration in rat calvaria with the critical-size defect was also evaluated in vivo using several comprehensive analyses in comparison with untreated $\mathrm{Mg}$ mesh. Following the application of protective $\mathrm{CaP}$ coating, the surface energy of Mg improved with higher hydrophilicity and cell affinity. At the same time, the CaP coating endowed Mg with higher Ca affinity and lower degradation. The $\mathrm{Mg}$ mesh with $\mathrm{CaP}$ coating had higher osteointegration and bone affinity than pristine Mg mesh.

Keywords: magnesium mesh, surface modification, calcium phosphate, guided bone regeneration, rat calvarial defect

\section{INTRODUCTION}

Guided bone regeneration (GBR) is an osteogenesis technique that has been developed from guided tissue regeneration, and it is used for regenerating new bone at sites with insufficient dimensions, heights, and bone volumes. Bone regeneration procedures, such as reconstruction of the bone structure after excision of ameloblastoma and jaw tumors, augmentation of the deficient height of alveolar ridges caused by periodontics, sinus elevation before implantation, and increase in jaw bone size horizontally or vertically before implantation at the site of tooth loss, are required in many patients undergoing oral and maxillofacial or orthopedic surgery (Miura et al., 2012). Using barrier membranes to form a secluded space is the key to this reconstructive procedure because the newly formed bone can be forced to collapse by the upper soft tissue of a large bone defect. Titanium alloys, cobalt-chromium alloys, and stainless steel are widely used as implant materials in traditional surgery. They have excellent mechanical strength, biostability, and durability, but they can cause stress-shielding effects, and additional surgery is often required to remove the implant after healing. Moreover, they can lead to the visualization of artifacts in magnetic resonance imaging and three-dimensional computed tomography technology, which is not conducive 
to bone structure monitoring and image evaluation (Hargreaves et al., 2011). Compared with the non-absorbable materials, the advantages of absorbable materials are evident. The latter can degrade in a physiological environment, reducing the need for additional removal surgeries and decreasing the incidence of secondary injuries to the wound; therefore, absorbable materials have been widely used in the biomedical field. However, the unpredictable resorption and unstable rigidity of absorbable materials can affect the structural integrity and barrier function of membranes (Rakhmatia et al., 2013). Therefore, a suitable GBR membrane is expected to not only have sufficient rigidity to reserve anatomic space at the site and exhibit bioactivity to boost new bone formation but also be able to degrade after bone regeneration is complete.

Magnesium (Mg) is a promising biomaterial and has attracted considerable research attention due to its excellent biodegradability, biocompatibility, and biomechanical properties (Staiger et al., 2006). Mg is the fourth most abundant metal ion in the human body, half of which is stored in the bone tissue, and the remaining excess ions are excreted through urine (De Baaij et al., 2015). The density of lightweight $\mathrm{Mg}$ is approximately $1.74 \mathrm{~g} / \mathrm{cm}^{3}$, and elastic modulus is $41-45 \mathrm{GPa}$. Both of these parameters are similar to those of the human bone $\left(1.8-2.1 \mathrm{~g} / \mathrm{cm}^{3}, 3-20 \mathrm{GPa}\right)$ and better than those of commonly used materials, such as titanium alloys $\left(4.4-4.5 \mathrm{~g} / \mathrm{cm}^{3}, 110-\right.$ $117 \mathrm{GPa})$ and stainless steel $\left(7.9-8.1 \mathrm{~g} / \mathrm{cm}^{3}, 189-205 \mathrm{GPa}\right)$ (Walker et al., 2014). Moreover, $\mathrm{Mg}$ also plays a regulatory role as a calcium-sensing receptor in the bone and calcium metabolism (Schlingmann, 2007). The history of biodegradable $\mathrm{Mg}$ implants began shortly after the discovery of $\mathrm{Mg}$ by Sir Humphrey Davy in 1808 (Witte, 2010). In 1878, Huse used $\mathrm{Mg}$ wire as a ligature to successfully stop bleeding in three patients and discovered the corrosive characteristics of $\mathrm{Mg}$ in the body (Bettman and Zimmerman, 1935). Since then, many studies have attempted to explore the in vivo application of $\mathrm{Mg}$ as miniscrews and cardiovascular stents (Witte, 2010). However, the rapid degradation of $\mathrm{Mg}$ in the physiological environment raises the problem of changing the $\mathrm{pH}$ around the implant and releasing gas, which not only reduces the mechanical strength but also increases the metabolic burden on human organs, thereby limiting its clinical applicability. Hence, many studies have focused on improving the corrosion resistance of $\mathrm{Mg}$ and its alloys using various methods.

Surface modification and alloying are the main methods used to control degradation and maintain mechanical properties in pure $\mathrm{Mg}(\mathrm{PM})$; however, it is difficult to achieve the required degree of corrosion resistance by alloying alone (Tian and Liu, 2015). Therefore, surface modification is used to form a degradable dynamic interface on $\mathrm{Mg}$-based materials, improving biocompatibility, imparting corrosion resistance, and maintaining mechanical strength; ultimately, such materials can be degraded without the release of any toxic by-products. Calcium phosphates (CaPs) have been used as coatings on implant surfaces because of their biocompatibility, bioactivity, and osteoconductive and osteoinductive properties (Jeong et al., 2019). CaP ceramics may also have the ability to induce appropriate host reactions to connect bone and materials via chemical bonding (Surmenev et al., 2014). Additionally, CaPs have chemical composition and properties similar to those of the mineral phase of human bones and teeth (Yang et al., 2005). Recently, CaPs have been successfully coated on AZ31, Mg-Zn, and AZ91D to improve their corrosion performance to different degrees of success (Xu et al., 2012).

The novelty of the current study is that the effect of $\mathrm{CaP}$ coating on pure $\mathrm{Mg}$, in the field of surface performance and in vivo osteointegration, was studied from the perspective of the material interface, as this is the first step when the implant material interacts with the host. A uniform and dense $\mathrm{CaP}$ protective coating was formed on the surface of PM meshes using a simple alkali-hydrothermal treatment. Surface-modified Mg meshes have excellent biocompatibility and improved corrosion resistance compared with untreated $\mathrm{Mg}$ meshes. In particular, samples treated for $2 \mathrm{~h}$ showed the best biological activity among various groups stratified according to treatment time. Based on the results, the 2-h group samples were selected to further investigate their application potential as biomedical materials using an animal model. The present study aimed to evaluate the performance difference between the $\mathrm{Mg}$ mesh subjected to alkali-hydrothermal treatment for $2 \mathrm{~h}$ and original $\mathrm{Mg}$ mesh, using in vivo and in vitro tests. The effect of the CaP coating layer on surface wettability, direct cell seeding, and ion release was evaluated. To further confirm and verify the advantages of $\mathrm{CaP}$ coating on the $\mathrm{Mg}$ surface over the untreated surface, a critical-size rat calvarial defect was used to evaluate the GBR of CaP-coated $\mathrm{Mg}$ mesh and the pure $\mathrm{Mg}$ mesh. Osteogenesis was assessed via quantitative and qualitative analyses of GBR employing microcomputed tomography (micro-CT) scanning, histomorphometry, and three-dimensional reconstruction.

\section{MATERIALS AND METHODS}

\section{Sample Preparation and Surface Modification}

Magnesium foils (99.9\% high purity) (Goodfellow, England), $100 \mathrm{~mm} \times 100 \mathrm{~mm} \times 0.1 \mathrm{~mm}$ in dimensions, were prepared by rolling and used as the substrate. The Mg foil was subjected to laser microprocessing to form a $\mathrm{Mg}$ mesh with a diameter of $10 \mathrm{~mm}$ and hole diameter of $0.4 \mathrm{~mm}$. According to the American Society for Testing and Materials (ASTM) standard (G1-03), chemical cleaning procedures were performed to remove the surface corrosion products and revitalize the surface. The Mg samples were directly placed into a beaker filled with a solution containing $0.25 \mathrm{~mol} / \mathrm{L}$ Ca-ethylenediaminetetraacetic acid (EDTA) $\left(\mathrm{C}_{10} \mathrm{H}_{12} \mathrm{CaN}_{2} \mathrm{Na}_{2} \mathrm{O}_{8}\right)$ and $0.25 \mathrm{~mol} / \mathrm{L} \quad \mathrm{KH}_{2} \mathrm{PO}_{4}$, and the solution was adjusted to a $\mathrm{pH}$ value of 8.9 with $\mathrm{NaOH}$. The alkaline-hydrothermal treatment was conducted at $90^{\circ} \mathrm{C}$ for $2 \mathrm{~h}$.

The microstructure and morphology of the $\mathrm{CaP}$ coating were identified using scanning electron microscopy (SEM; JSM-5900, JEOL, Japan). The cross-section of surface-modified $\mathrm{Mg}$ was sputtered with platinum coating, following which 
the cross-sectional morphological microstructure was observed using field emission scanning electron microscopy (FE-SEM; SU-70, HITACHI, Japan), while the elemental composition of the designated localized area on the cross-section was investigated using energy dispersive spectroscopy with FE-SEM.

\section{Implant-Body Fluid Interface Analysis}

The initial contact between the implant and host is at the interface between the sample and body fluid. The surface property of the implant is an important consideration for its clinical applicability, which can affect the surface wettability, tissue adhesion, and the release of active ingredients of biomaterials. Therefore, the surface difference between PM and coated $\mathrm{Mg}$ (CM) was evaluated by the contact angle, direct cell seeding, and ion release tests.

\section{Wettability}

The hydrophilicity of the sample surface was evaluated by the contact angles of dropping the cell culture medium on prepared samples to determine the wettability of the sample. To prevent oil or pollution from the skin and environment from affecting the sample surfaces, it was necessary to use $70 \%$ ethanol to clean the sample placement plane and use forceps to place the samples. Contact angles and images were obtained by the touch drop method using a contact angle analyzer (Phoenix-300 Touch, Surface Electro Optics, South Korea).

\section{Cell Adhesion}

The mouse osteoblast cell line, MC3T3-E1, obtained from the American Type Culture Collection, was used directly for seeding onto the prepared sample surface to evaluate cell adhesion and the changes in surface morphological. MC3T3-E1 cells were maintained in a culture medium at $37^{\circ} \mathrm{C}$ in a humidified atmosphere containing $5 \% \mathrm{CO}_{2}$. Cells were cultured in $\alpha$-minimum essential medium (Gibco Co., Carlsbad, CA, United States) supplemented with $10 \%$ fetal bovine serum (Gibco Co.), $500 \mathrm{U} / \mathrm{ml}$ penicillin (Gibco Co.), and $500 \mathrm{mg} / \mathrm{ml}$ streptomycin (Gibco Co.).

After sterilizing the prepared samples with ultraviolet (UV) radiation for 30 min per side, the samples were placed in 24-well cell culture plates. Next, MC3T3-E1 cells at a density of $1.5 \times 10^{4}$ cells $/ \mathrm{ml}$ were carefully seeded onto the sample surfaces (three wells per group). The cultures were incubated at $37^{\circ} \mathrm{C}$ in a $5 \%$ $\mathrm{CO}_{2}$ incubator for 3 days. The morphology of the cells adhered to the samples was observed using SEM. The samples were washed twice with phosphate-buffered saline (PBS) and fixed with 2.5\% glutaraldehyde (GA) for $2 \mathrm{~h}$ at $4^{\circ} \mathrm{C}$. After removing $\mathrm{GA}$ and washing twice with PBS, the cells were fixed with $1 \%$ osmium for $2 \mathrm{~h}$ at $4^{\circ} \mathrm{C}$. Following dehydration with gradient ethanol $(30,50$, $70,80,90$, and $100 \%$ ) for $10 \mathrm{~min}$ each at $4^{\circ} \mathrm{C}$, the samples were ion sputtered and analyzed by SEM.

\section{Release Test}

Both sides of PM and CM were sterilized by UV radiation for $30 \mathrm{~min}$ before performing corrosion tests. The tests were performed by soaking the prepared samples in Earle's balanced salt solution (EBSS) and incubating at $37^{\circ} \mathrm{C}$ in $5 \% \mathrm{CO}_{2}$. EBSS
$(1 \times)$ was prepared following the manufacturer's instructions of commercial EBSS $10 \times$ (E7510, Sigma, United States). Prepared samples were immersed in a solution in which the ratio of media volume to sample surface area is $0.255 \mathrm{ml} / \mathrm{mm}^{2}$ [more than the minimum of $0.20 \mathrm{mml} / \mathrm{mm}^{2}$ (ASTM International, 2012)]. $\mathrm{Mg}$ and $\mathrm{Ca}$ concentrations in EBSS, before and after immersion, were quantitatively analyzed using an inductively coupled plasma-optical emission spectrometer (ICP-OES; Agilent 7500a, Agilent Technologies, Wilmington, DE, United States). Samples were collected after by taking out 1-ml aliquots and then replacing them with $1 \mathrm{ml}$ of fresh EBSS. All measurements were performed in triplicate.

\section{In vivo Analyses}

Sixteen Mg meshes manufactured were divided into PM and $\mathrm{CM}$ mesh groups for in vivo studies. Male Sprague-Dawley rats, aged 8 weeks and weighing $250 \pm 20 \mathrm{~g}$, were used as experimental subjects. One week before the experiment, the rats were housed in the animal room at a constant temperature, humidity, and standard light-dark schedule to acclimatize them to the environment.

All animal experiments were conducted under ethical clearance, which was approved by the Institutional Animal Care and Use Committee of the Jeonbuk National University, Laboratory Animal Center, Jeonju-si, South Korea (approval number: CBNU 2020-008).

\section{Procedures}

The surgery was conducted under aseptic conditions. All samples were sent to the hospital disinfection room (Jeonbuk National University Hospital) for ethylene oxide sterilization before performing the in vivo tests.

An 8-mm critical size defect was created surgically, as described in previous studies (Wu et al., 2019). After intramuscular injection of $50 \mathrm{mg} / \mathrm{kg}$ of Zoletil (Zoletil 50, Virbac Laboratories, France) and $15 \mathrm{mg} / \mathrm{kg}$ of xylazine hydrochloride (Rompun, Bayer, South Korea) to induce general anesthesia, the skin at the surgical site was shaved and then disinfected with iodine scrubs. Additional local anesthesia $(0.5 \mathrm{ml}$ of $1 \%$ lidocaine) was injected on the calvaria to aid the effects of anesthesia and reduce hemorrhaging. A $2-\mathrm{cm}$ incision was created from the lambda to the middle of the nasal bones, and the periosteum was bluntly dissected to expose the calvaria. The critical-size defect was performed using a trephine bur connected to an endodontic motor (X-SMART, Dentsply, Switzerland) under copious saline irrigation. The edges of the 8-mm-diameter defect were checked carefully and washed to remove residual bone debris. Care was taken to avoid damaging the dura or brain under the bone. The defect was completely covered by mesh, and the periosteum was positioned over the mesh and sutured with bioabsorbable silk (5-0 glyconate monofilament, B. Braun, Rubí, Spain), following which the skin was closed using a non-absorbable nylon silk (4/0 blue nylon, Ailee Co., Ltd., Busan, South Korea). To prevent infection, antibiotics (amikacin; Samu Median Co., Ltd., South Korea) were administered subcutaneously for 3 days postoperatively. The rats were sacrificed at 4 and 8 weeks by euthanization 
with an overdose of thiopental sodium (Choongwae Pharma Corporation, Seoul, South Korea).

\section{Micro-CT}

The excised blocks, $20 \mathrm{~mm} \times 20 \mathrm{~mm}$ in dimensions, were stored in $10 \%$ formalin before being dispatched to the Center for University-Wide Research Facilities at Jeonbuk National University. For quantitative and qualitative analyses, micro-CT (Skyscan 1076) was used to examine the dissected specimens at an $18-\mu \mathrm{m}$ resolution with a $1-\mathrm{mm}$ aluminum filter. The blocks were scanned at $100 \mathrm{kV}$ voltage and $100 \mu \mathrm{A}$ current with $360^{\circ}$ scanning rotation. The three-dimensional images were reconstructed and analyzed using the NRecon reconstruction program and CT-analyzer software (SkyScan, Aartselaar, Belgium). Regions of interest (ROIs) were created by manually drawing in the region of the $8-\mathrm{mm}$ critical defect to distinguish the newly formed bone and $\mathrm{Mg}$ mesh. Three-dimensional images were reconstructed using the CTvox program (SkyScan).

\section{Histological Analysis}

After micro-CT scanning, the blocks obtained in each group were subjected to a series of fixation, staining, and embedding processes for performing histological analysis.

After micro-CT scanning, the blocks were fixed in fresh $10 \%$ formalin for 2 days and stained using Villanueva solution (Polysciences, Inc., Eppelheim, Germany). The blocks were then dehydrated with gradient ethanol (80, 90, 95, and $100 \%)$ and $100 \%$ acetone. To embed the blocks in resin, the blocks were prepermeated with methylmethacrylate (MMA, Yaruki Pure Chemicals Co., Ltd., Kyoto, Japan) under vacuum for $2 \mathrm{~h}$ and then infiltrated with the polymerization mixture (PMMA) at $35^{\circ} \mathrm{C}$ for 3 days followed by $60^{\circ} \mathrm{C}$ for 1 day. Prepared resin blocks were cut into $0.7-\mathrm{mm}$ thick slices through the central line of the defect using a low-speed saw (EXAKT 300 CP, EXAKT Technologies
Inc., Norderstedt, Germany). Slices were ground to $70-\mu \mathrm{m}$ thickness for histological analysis using a microgrinding system (EXAKT 400 CS, EXAKT Technologies Inc.). Histomorphometric analysis was conducted using optical microscopy $(10 \times$ magnification and $30 \times$ magnification; EZ4D, Leica, Wetzlar, Germany).

\section{Statistical Analyses}

The data are presented as the mean \pm standard deviation (SD). One-way ANOVA with post hoc Tukey's test was performed, and $p<0.05$ was considered statistically significant.

\section{RESULTS}

Figure 1 shows the results of the surface morphology and cross-sectional elemental distribution of CM. After $2 \mathrm{~h}$ of alkalihydrothermal treatment, the rod-like particles assembled to form a dense and uniform coating layer with a cauliflowerlike structure. The thickness of the coating was in the range of 1.5-2.2 $\mu \mathrm{m}$, and two distinct strata consisting of the dense inner layer and rod-like irregular orientation outer layer were visible. Elemental mapping showed the distribution of $\mathrm{Ca}, \mathrm{P}, \mathrm{O}$, and $\mathrm{Mg}$ in the cross-section. The line profiles of $\mathrm{Ca}$ and $\mathrm{P}$ showed broad peaks in the outer layer of the coating, while those of $\mathrm{Mg}$ and $\mathrm{O}$ showed broad peaks in the inner layer. The interface between the $\mathrm{Mg}$ substrate and coating was not straight, indicating that a corrosion reaction occurred. The elemental distribution of the point profile showed that $\mathrm{Mg}$ mainly existed in the inner layer of the coating, indicating that $\mathrm{Mg}(\mathrm{OH})_{2}$ was formed at the interface between the $\mathrm{Mg}$ substrate and coating after $2 \mathrm{~h}$ of alkali-hydrothermal treatment.

The wettability of the sample surface (Figure 2) was evaluated by the touch drop method and presented as optical images and contact angles. The results show that the hydrophilic CaP
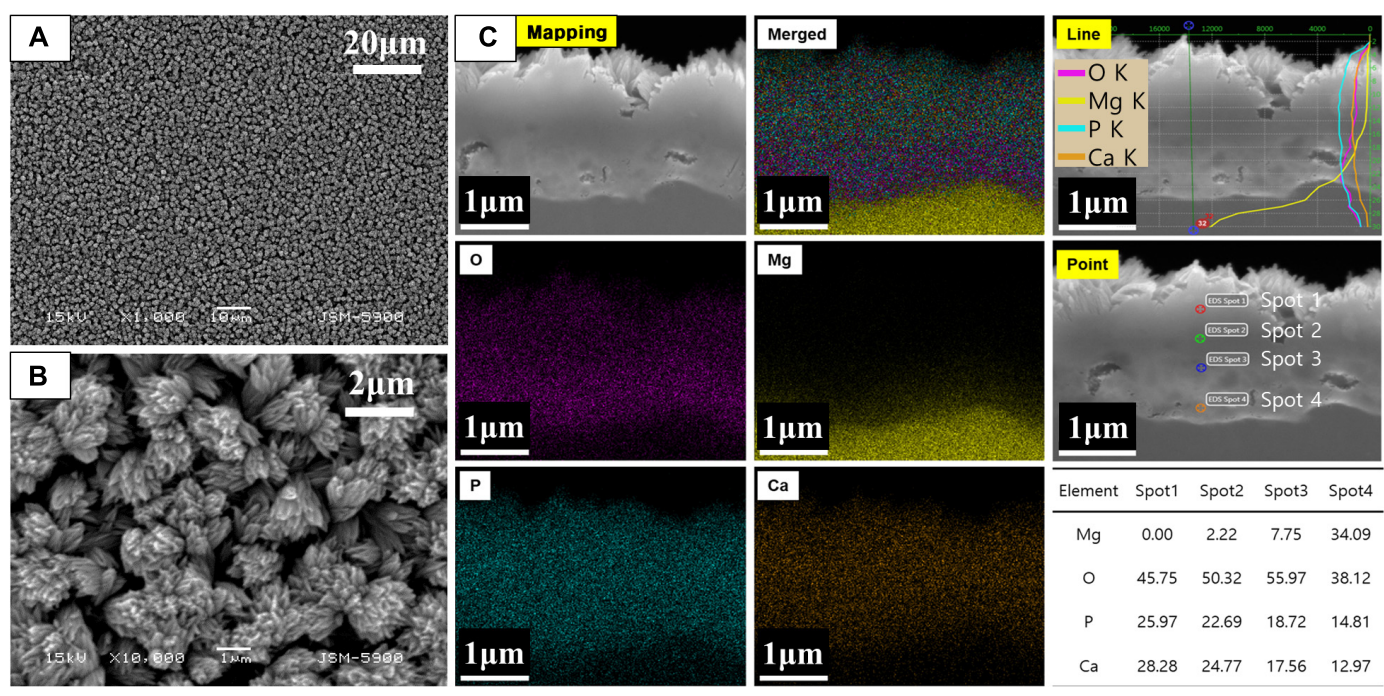

FIGURE 1 | (A,B) Surface morphology and (C) cross-sectional elemental analysis of CaP-coated Mg after alkali-hydrothermal treatment for 2 h. 


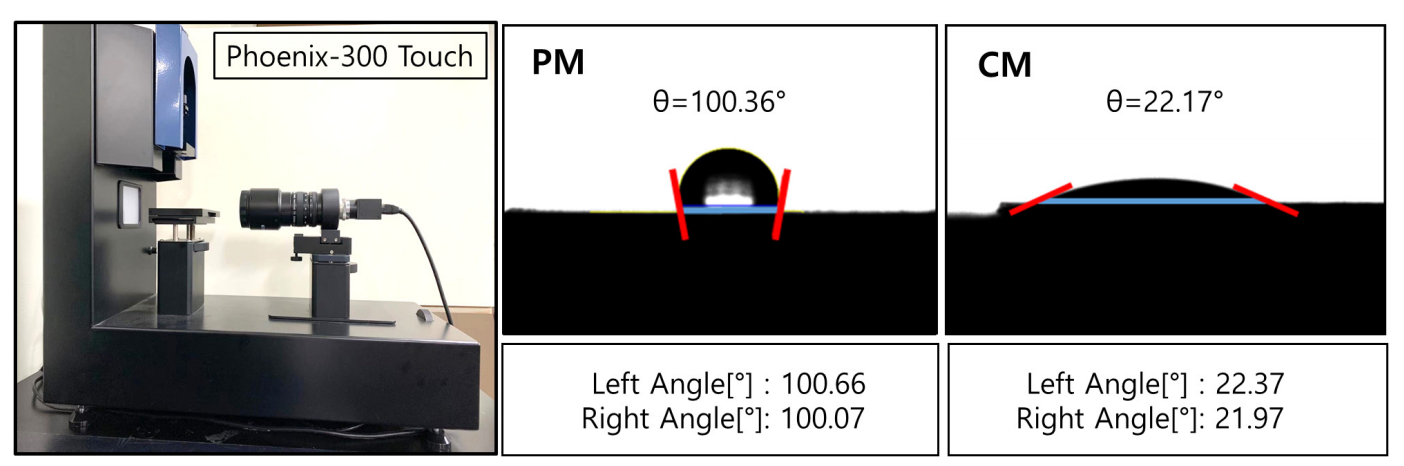

FIGURE 2 | Contact angles of PM and CM were measured using Phoenix-300 Touch, representing the hydrophilicity of the sample surface. PM, pure magnesium; $\mathrm{CM}$, calcium-phosphate-coated magnesium.

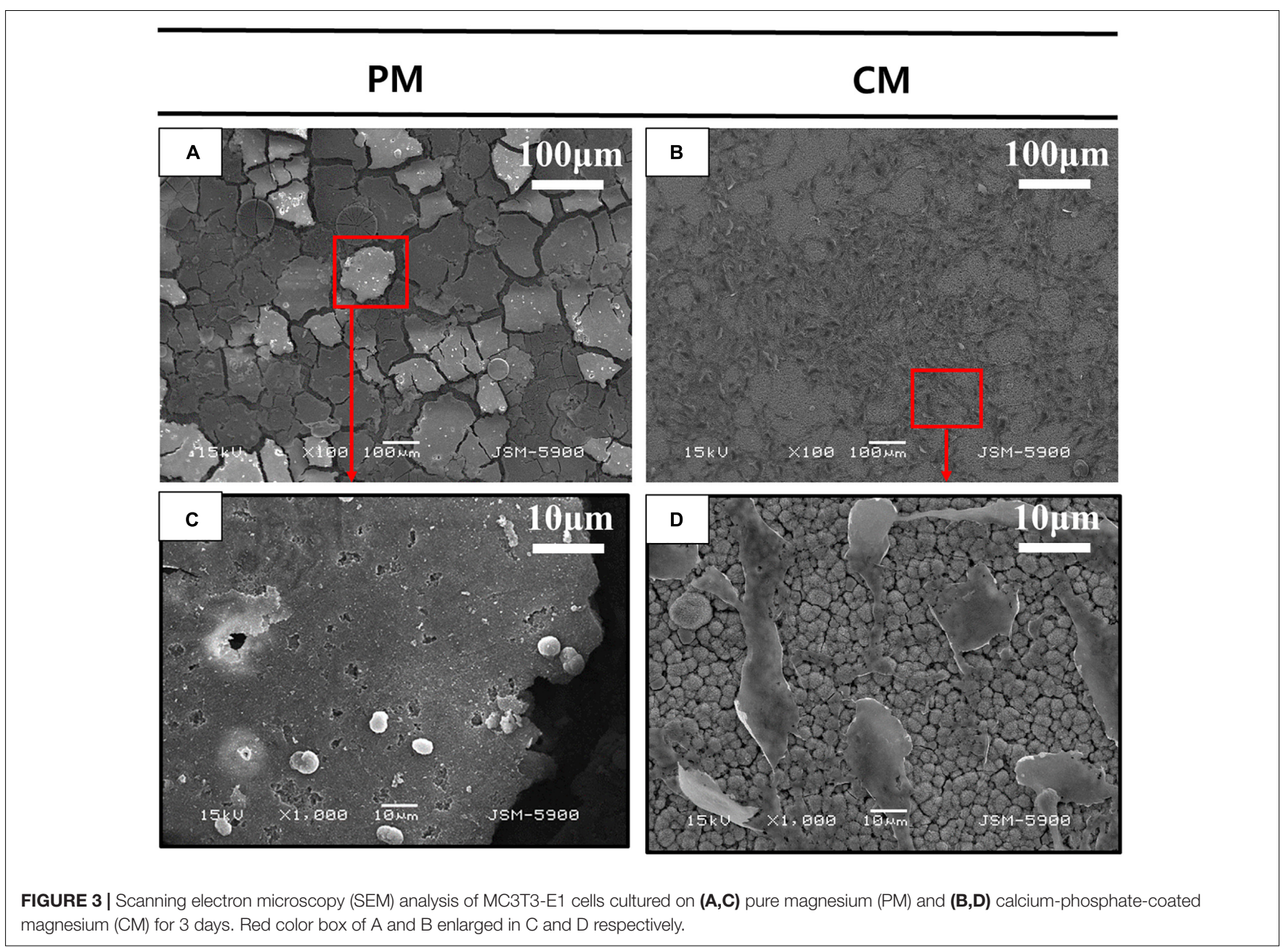

coating reduced the contact angle of $\mathrm{CM}$ to $22.69 \pm 2.27^{\circ}$, which significantly improved the wettability of CM compared to that of $\operatorname{PM}\left(105.66 \pm 7.86^{\circ}\right)$.

Figure 3 shows the attachment of MC3T3-E1 cells on PM and CM after 3 days of cell culture observed by FE-SEM. Images obtained at $100 \times$ magnification showed the attachment of numerous cells and improved cell distribution on the surface of
CM compared to that of PM. The morphology of MC3T3-E1 cells cultured on CM showed an elongated shape without filopodia extensions, indicating that the cells were in a state of proliferation. However, in PM, many cells were not found on the surface; in addition, the material appeared to be severely degraded. The few cells detected on PM were white in color and round in shape, indicating cell death and detachment. 


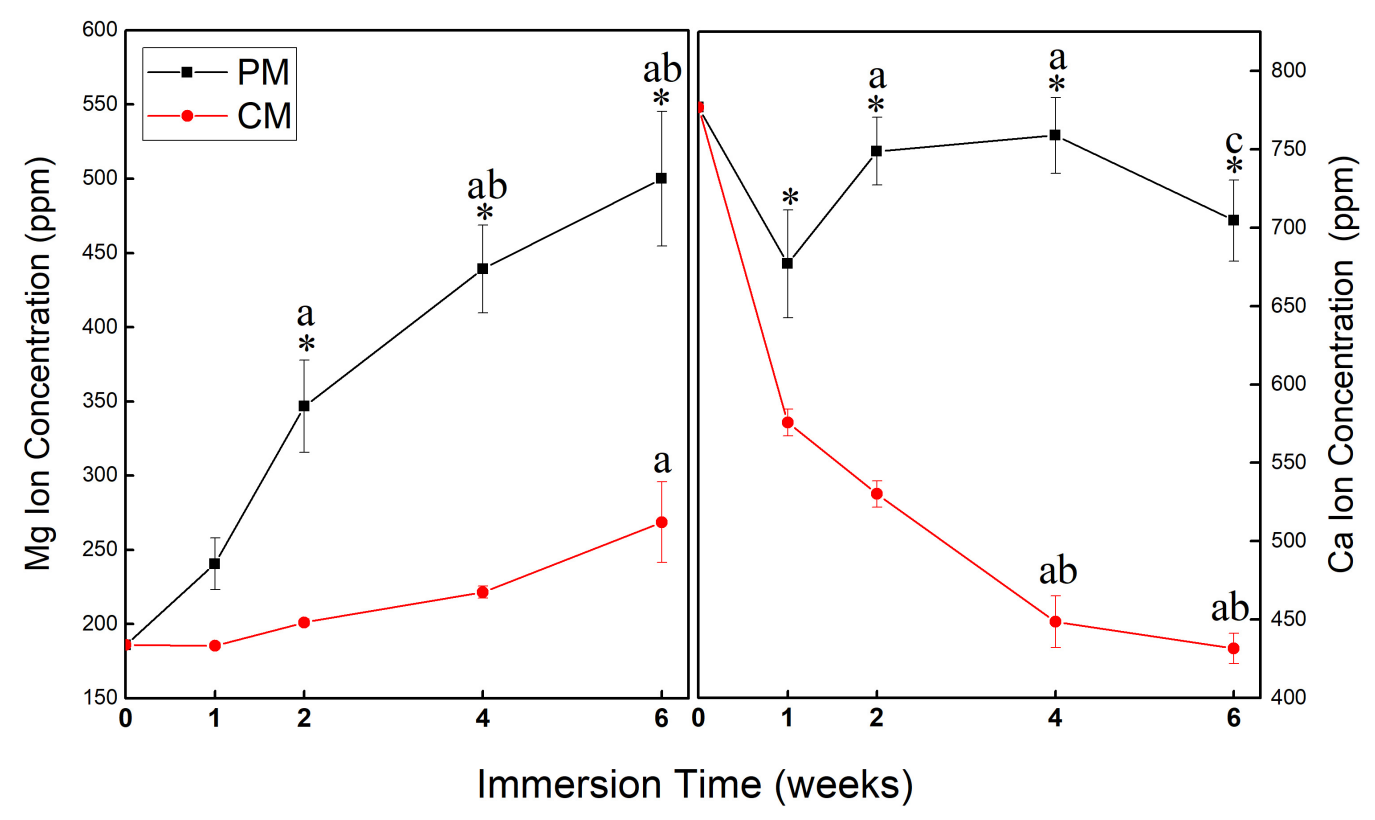

FIGURE 4 | Changes in the concentration of Mg and Ca ions in Earle's balanced salt solution (EBSS) during the 6-week ion release test of pure magnesium (PM) and calcium-phosphate-coated magnesium (CM) (* indicates significant difference between PM and CM; a indicates significant differences compared to 1 week; $b$ indicates significant differences compared to 2 weeks; c indicates significant differences compared to 4 weeks).

Figure 4 shows changes in the concentration of $\mathrm{Mg}$ and $\mathrm{Ca}$ ions in EBSS during the 6-week ion release test of PM and CM. ICP-OES test data showed that the release amount and rate of $\mathrm{Mg}$ ions from PM were significantly higher than those from CM, indicating that $\mathrm{CM}$ had excellent corrosion resistance. At 1 week of immersion in EBSS, the concentration of Ca ions in the PM $(677.04 \pm 34.46)$ and CM $(575.82 \pm 8.50)$ groups was lower than that in EBSS initially (776.88 ppm). However, the concentration of $\mathrm{Ca}$ ions in the PM group began to increase after 1 week, which indicated that deposited $\mathrm{Ca}$ ions continued to be released along with the degradation of PM. The concentration of $\mathrm{Ca}$ ions in the CM group continued to decrease throughout the test period, which indicated that $\mathrm{CaP}$ coating significantly improved the corrosion resistance of $\mathrm{Mg}$ and made surface-modified $\mathrm{Mg}$ with favorable calcium affinity.

Quantitative assessment was performed using micro-CT to investigate bone reconstruction within the ROI in rat calvaria. As shown in Figure 5, both the new bone volume and mineral density in the 8 - $\mathrm{mm}$ critical-size defect of rat calvaria placed with PM and CM increased with time. New bone volume in the CM group was significantly higher than that in the PM group at 4 weeks postsurgery $(p \leq 0.05)$. From 4 to 8 weeks, even if the amount of new bone formation in the CM group increased significantly, there was no significant difference compared with the PM group. In terms of bone mineral density, there was no significant difference between the CM and PM groups.

To confirm the residual amount of $\mathrm{Mg}$ mesh, the ROI was manually drawn to mark the placement of $\mathrm{Mg}$ mesh in the rat calvarial model based on micro-CT data. The $\mathrm{Mg}$ meshes of all groups showed time-dependent degradation, and the volume of $\mathrm{Mg}$ in all groups decreased during each assessed period. As shown in Figure 6, the corrosion speed of PM was fast. The residual $\mathrm{Mg}$ volume of $\mathrm{PM}$ was $3.74 \pm 0.12 \mathrm{~mm}^{3}$ at 8 weeks, and the percentage of $\mathrm{Mg}$ degradation reached $58.49 \%$. However, the residual $\mathrm{Mg}$ volume of $\mathrm{CM}$ was $7.02 \pm 0.75 \mathrm{~mm}^{3}$, and percentage of $\mathrm{Mg}$ degradation reached $21.98 \%$. These results were consistent with the three-dimensional reconstructed microCT image showing that the PM meshes experienced severe degradation after implantation (Figure 6B).

Figures 7, 8 show bone formation in the rat calvarial defect from the perspective of overall and partial views, respectively. In the three-dimensional reconstruction image of CTvox (see Figure 7), new bone formation can be observed above and beneath the Mg mesh, and both the area of new bone and residual mesh volume in the CM group were higher than those in the PM group. In addition, the partial views in Figure $\mathbf{8}$ show the relationship between the membrane and new bone in the CM group in which CM led to the generation of a dense and regular new bone layer and also had a direct contact between the mesh and newly formed bones. However, because gas was released when $\mathrm{Mg}$ was degraded in the physiological environment, it created a gap between the new bone layer and mesh (Figure 8). In particular, the severe degradation of PM led to a large gap between the new bone and mesh in the PM group.

\section{DISCUSSION}

Previous studies on $\mathrm{Mg}$ have mainly focused on the development of $\mathrm{Mg}$ alloys to improve surface properties and corrosion protection because alloying is an effective method to improve the mechanical strength of Mg. However, it is difficult to achieve 


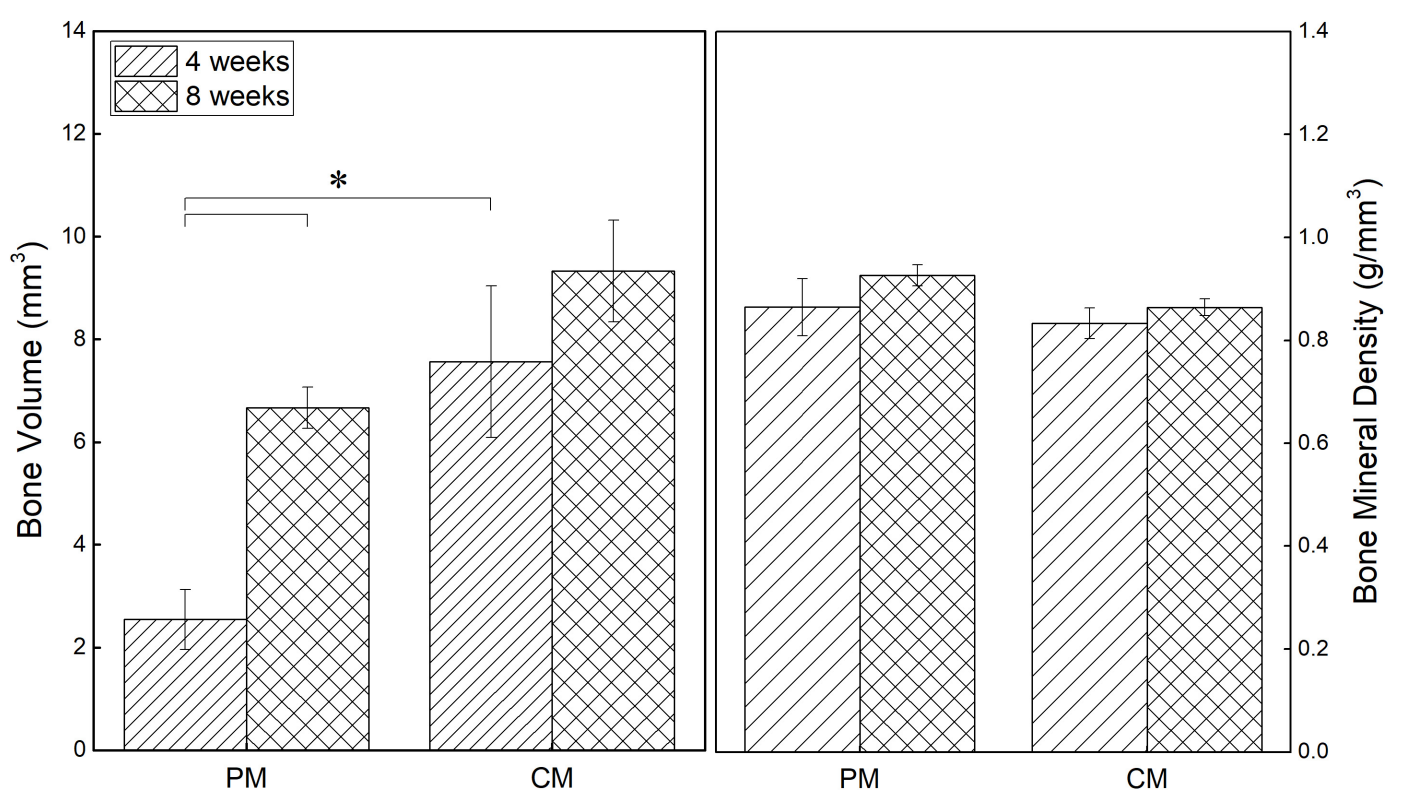

FIGURE 5 | Quantitative analysis results of new bone volume and mineral density in the critical-size defects of rat calvaria obtained from micro-CT data ( ${ }^{\star} p \leq 0.05$ ).

the desired degree of corrosion resistance by alloying alone since thin $\mathrm{Mg}(\mathrm{OH})_{2}$ formed spontaneously on the surface can be easily destroyed in the physiological environment including chloride ions, as well as microgalvanic corrosion can occur due to the different potential between $\mathrm{Mg}$ matrix and alloy elements (Gusieva et al., 2015). Furthermore, to improve the mechanical strength of $\mathrm{Mg}$ alloys, some components such as aluminum (Abd El-Rahman, 2003) are added, which increases the uncertain toxicity of commercial Mg alloys (Song, 2007). Therefore, to improve not only corrosion resistance but also biostability and biosafety, $\mathrm{CaP}$ coating was produced on PM, which has been previously confirmed to be effective in controlling early corrosion (Gan et al., 2013) and improving bioactivity (Lorenz et al., 2009).

Recent studies have investigated $\mathrm{CaPs}$ as a long-term biocompatibility coating on PM. Zhang et al. (2009) found that biomimetic $\mathrm{CaP}$ coating could increase corrosion protection compared with untreated Mg. Gan et al. (2013) showed that bioactive coating with $\mathrm{Ca}$ and $\mathrm{P}$ on PM was relatively dense and uniform and significantly enhanced corrosion resistance in Hank's solution. In the study conducted by Lorenz, the protective layer containing $\mathrm{CaP}$ was formed by soaking $\mathrm{Mg}$ in simulated body fluid for 5 days, leading to favorable initial cell adhesion to samples, but poor protective properties of this layer prevented long-term cell survival (Lorenz et al., 2009). Research on the biocompatibility, biosafety, and biostability of $\mathrm{Mg}$ also plays a role in the study of bioabsorbable implants for biomedical applications. It has been shown that amorphous $\mathrm{CaP}$ coating on PM mesh significantly retards the biodegradation of PM and improves bone formation in rat calvaria ( $\mathrm{Wu}$ et al., 2019). A protective CaP coating was formed on PM through a simple alkali-hydrothermal treatment, which not only effectively increased the ratio of $\mathrm{Ca}$ and $\mathrm{P}$ but also improved corrosion resistance and biocompatibility. In particular, $\mathrm{Mg}$ after alkalihydrothermal treatment for $2 \mathrm{~h}$ induced excellent differentiation and proliferation of MC3T3-E1 cells, indicating that $\mathrm{Mg}$ has high biocompatibility and biosafety and is suitable for further exploration in bone tissue engineering.

In tissue engineering, the scaffold substrates are mostly dependent on the surface features of materials. The initial interaction immediately occurs between the host tissue and surface of the barrier membrane when the material is placed in the human body and exposed to body fluid, followed by a series of cell-material interactions. Hence, the implant-body fluid interface has a profound impact on the biocompatibility of biomaterials, and the surface properties of materials influence the biological response of the host. Following the application of CaP coating, a series of experiments were performed on the implant-body fluid interface to determine the energy of the surface of $\mathrm{Mg}$ in this study. The surface energy generated by the external unsaturated bond is higher than its internal energy. Therefore, when a liquid is placed on a low-energy surface metal, the contact angle is higher than that of a high-energy surface metal (Mekayarajjananonth and Winkler, 1999). When the hydrophobic solid surface of PM with a contact angle of $105.66 \pm 7.86^{\circ}$ (higher than $90^{\circ}$ ) changed to a hydrophilic surface of $\mathrm{CM}$ with a contact angle of $22.68 \pm 2.27^{\circ}$, the $\mathrm{CaP}$ coating significantly improved the wettability and surface energy of $\mathrm{Mg}$ (Figure 2). Moreover, HAp coating can induce cell attachment, proliferation, and differentiation and increase the activity of osteoblasts (Kim et al., 2014). As shown by the results of the direct cell test (Figure 3), the stable hydrophilic surface of $\mathrm{CM}$ has the advantage of inducing cell attachment and cell spreading compared to the hydrophobic surface of PM. This is consistent with previous studies showing that hydrophilic materials with 


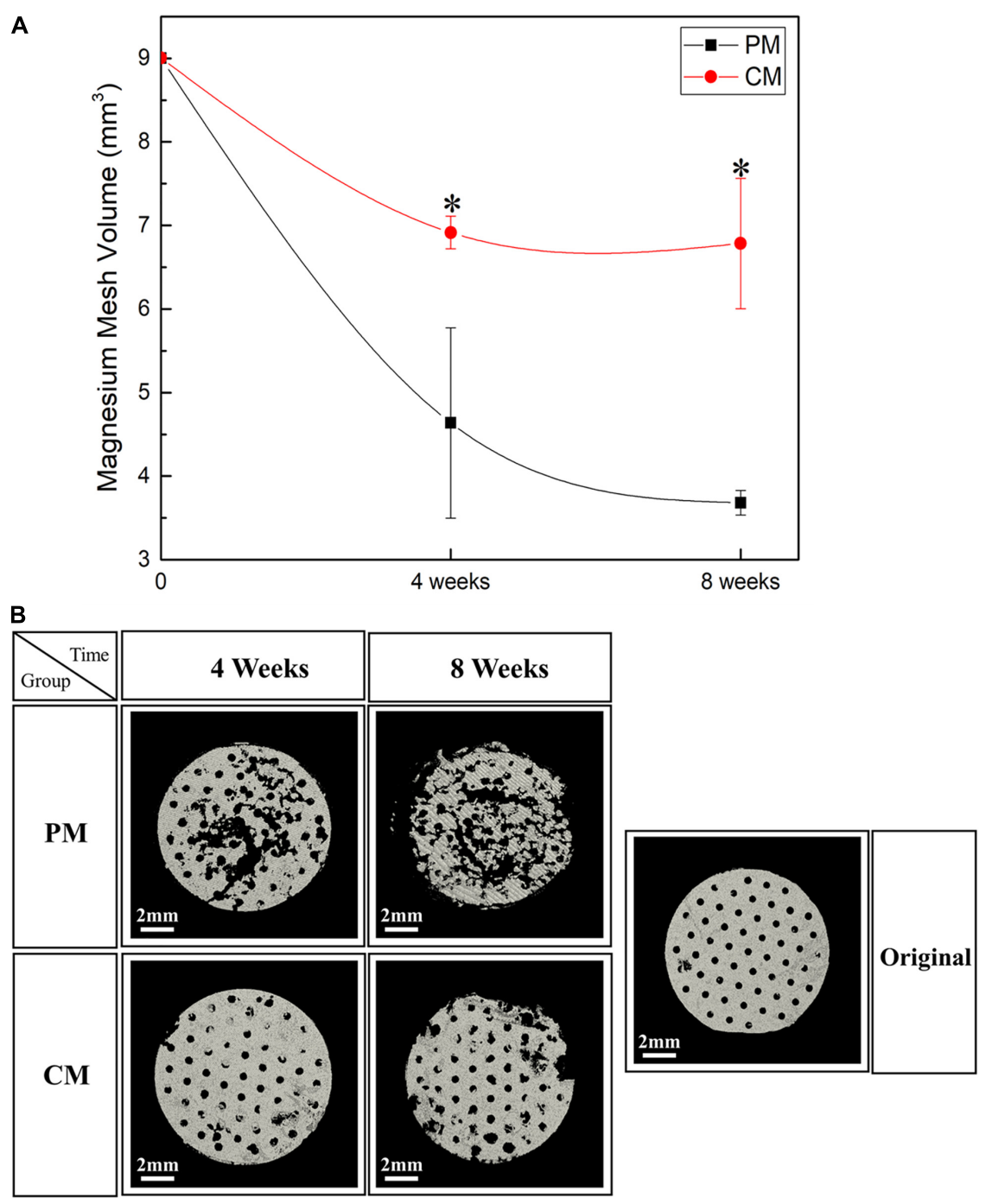

FIGURE 6 | (A) Quantitative analysis results and (B) three-dimensional reconstruction images of the Mg meshes used in the rat calvarial model for guided bone regeneration obtained using micro-CT [ ${ }^{*}$ indicates significant difference between pure magnesium (PM) and calcium-phosphate-coated magnesium (CM)].

low water contact angles can promote cell adhesion (Ishizaki et al., 2010), spreading (Amornsudthiwat et al., 2013), and proliferation (Watanabe et al., 2012; Kim et al., 2016). Cell adhesion and surface interaction with biomaterials in tissue engineering are mainly attributed to the wettability of materials (Aronov et al., 2006).

During the 6 weeks of the release test, the concentration of $\mathrm{Mg}$ ions in the PM group continuously increased to 500.12 \pm 45.26 , while the concentration of $\mathrm{Mg}$ ions in the $\mathrm{CM}$ group did not increase $(268.56 \pm 27.07)$. This indicates that the release of $\mathrm{Mg}$ ions was significantly reduced by the protective $\mathrm{CaP}$ coating in the $\mathrm{CM}$ group. At 1 week of immersion, $\mathrm{Mg}$ ion concentration in the CM group was $185.46 \pm 1.87$, which was close to the initial $\mathrm{Mg}$ ion concentration of 185.81 due to the deposition of $\mathrm{Mg}$ ions on the surface of $\mathrm{CM}$ owing to their affinity toward electronegative ions such as $\mathrm{OH}^{-}$and $\mathrm{PO}_{4}{ }^{3-}$. Ca ion concentration in all groups decreased after
1 week of EBSS immersion. In previous studies, $\mathrm{CaP}$ coating has displayed bioactivity in simulated body solutions. Ca ions were released into the peri-implant region in the initial stage of implantation, resulting in local supersaturation of $\mathrm{Ca}$ ions. Next, the ions were redeposited from the simulated body solution into the implant, which triggered HAp formation (Cazalbou et al., 2005; Paital and Dahotre, 2009). However, the first ion assessment in the current study was carried out after 1 week of immersion, which is markedly beyond the 2 days of immersion assessed in the previous study (Nguyen et al., 2013). This might be the reason why the initial release of $\mathrm{Ca}$ ions was not detected in the current study, yet the deposition and concentration reduction in $\mathrm{Ca}$ ions were detected (Figure 6). The redeposition layer was a biological apatite layer produced by a biomimetic coating method. Two factors contributed to this layer: (i) $\mathrm{CaP}$ coating in $\mathrm{CM}$ provided nucleation sites for further deposition of apatite and (ii) the alkaline environment 

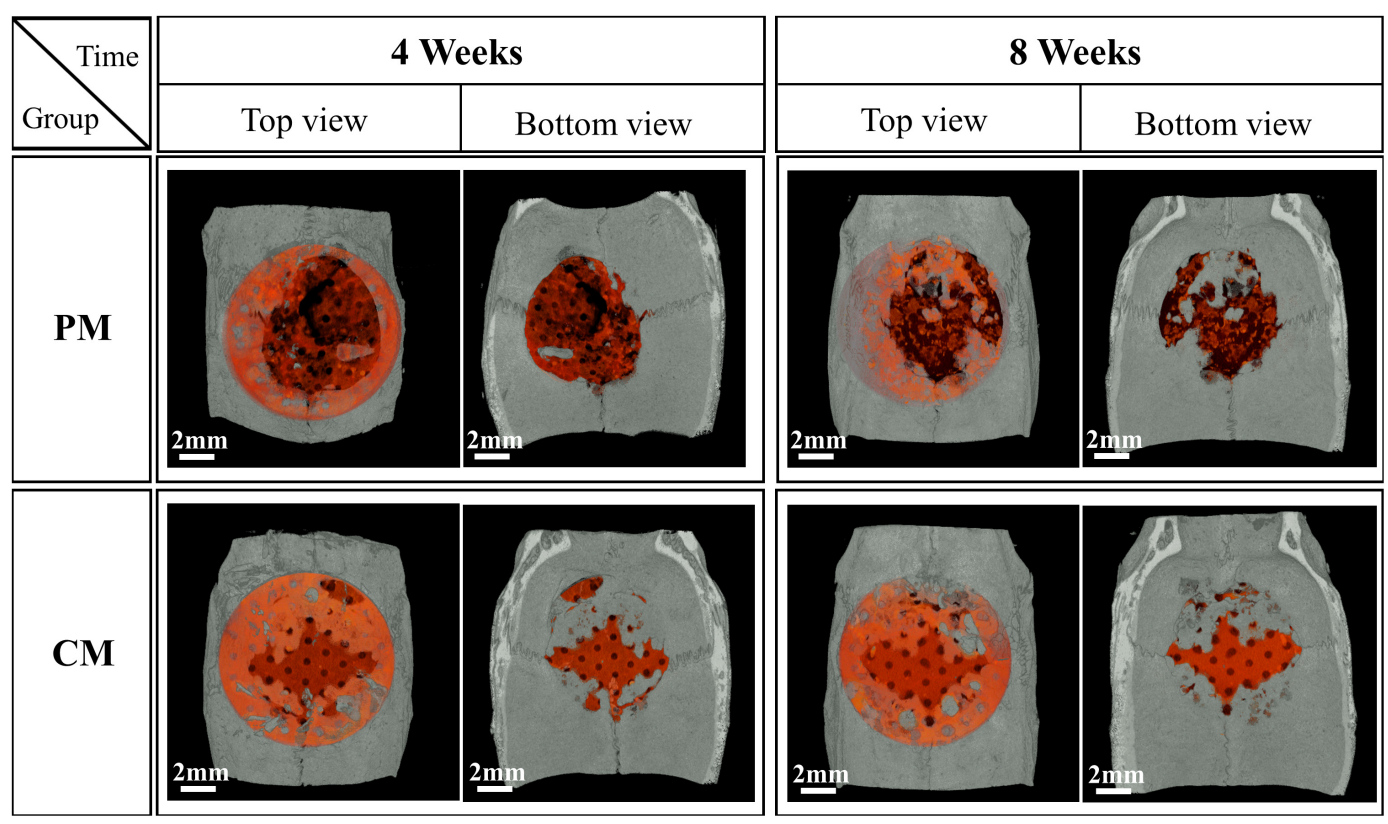

FIGURE 7 | Micro-CT images of the morphology of degraded Mg mesh and newly formed bone in the rat calvaria. The degraded Mg mesh is highlighted in orange.
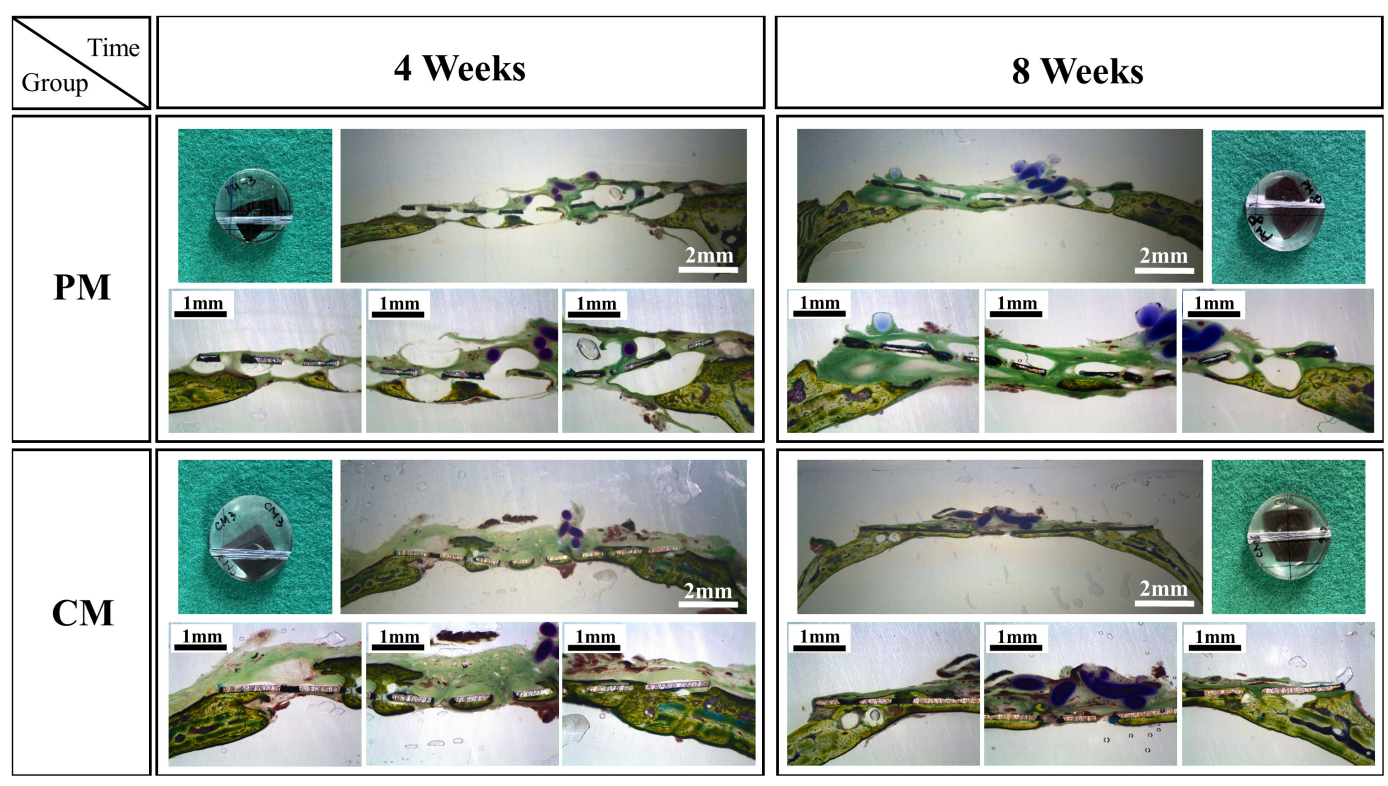

FIGURE 8 | Histological cross-sectional images of bone formation in the pure magnesium (PM) and calcium-phosphate-coated magnesium (CM) groups after 4 and 8 weeks of implantation. Histomorphology is presented as $10 \times$ magnification of coronal slices and focal areas of the center and side points ( $30 \times$ ).

processed into $\mathrm{CM}$ provided the necessary functional groups (such as $\mathrm{H}_{2} \mathrm{PO}_{4}^{-}$and $\mathrm{OH}^{-}$) for apatite formation (Tanahashi and Matsuda, 1997). As a result (Figure 3D), the structure of CM changed slightly after incubation for 3 days and could induce cell attachment, proliferation, and differentiation to form new bones (Paital and Dahotre, 2009).

After placing meshes for 4 and 8 weeks (Figures 7, 8), a new bone was formed above and beneath the surface-treated meshes and was in close contact. This indicates that the $\mathrm{CaP}$ coating has a high affinity for osteoblasts, resulting in osteointegration at the implant-host tissue interface. The degradation of $\mathrm{Mg}$ is inevitably accompanied by gas release $\left(\mathrm{Mg}+2 \mathrm{H}_{2} \mathrm{O} \rightarrow \mathrm{Mg}^{2+}+2 \mathrm{OH}^{-}+\mathrm{H}_{2} \uparrow\right)$, which results in the detachment of newly formed bone or osteoblasts from the mesh. Especially in PM (Figure 8), the large amount of gas produced pushed osteoblasts far away from the mesh, generating 
a gap between the new bone layer and mesh. After implantation in rat models, the mesh volume of CM and PM decreased after the biodegradation of $\mathrm{Mg}$. By calculating the residual $\mathrm{Mg}$ volume, the extent of degradation in CM was lower than that in PM (Figure 6); this is because $\mathrm{CM}$ with a protective $\mathrm{CaP}$ coating exhibited high corrosion resistance. In addition, excessive $\mathrm{Mg}$ ion release during corrosion of the uncoated sample possibly inactivated new bone formation (Serre et al., 1998; Wong et al., 2010), thereby resulting in less new bone formation around the PM compared with the CM. The high osteoblast affinity of coating in $\mathrm{CM}$ also contributed to the higher bone volume in CM. Within 4-8 weeks, even if the volume of new bone formed in CM significantly increased, there was no significant difference compared with PM. This may be attributed to the time-dependent degradation of the CaP coating.

\section{CONCLUSION}

The results of this study demonstrate that the corrosion rate and osteogenesis capability of $\mathrm{Mg}$ in the physiological environment can be tailored by using a simple alkali-hydrothermal treatment. $\mathrm{CaP}$ coating of $\mathrm{Mg}$ favors cell attachment and cell spreading. The formation of a bioactive $\mathrm{CaP}$ coating can endow $\mathrm{Mg}$ with higher surface energy and osteogenesis capability and lower degradation than PM.

\section{REFERENCES}

Abd El-Rahman, S. S. (2003). Neuropathology of aluminum toxicity in rats (glutamate and GABA impairment). Pharmacol. Res. 47, 189-194. doi: 10.1016/ s1043-6618(02)00336-5

Amornsudthiwat, P., Mongkolnavin, R., Kanokpanont, S., Panpranot, J., San Wong, C., and Damrongsakkul, S. (2013). Improvement of early cell adhesion on Thai silk fibroin surface by low energy plasma. Colloids Surfaces B: Biointerfaces 111, 579-586. doi: 10.1016/j.colsurfb.2013. 07.009

Aronov, D., Rosen, R., Ron, E., and Rosenman, G. (2006). Tunable hydroxyapatite wettability: effect on adhesion of biological molecules. Process Biochem. 41, 2367-2372. doi: 10.1016/j.procbio.2006.06.006

ASTM International. (2012). NACE/ASTMG31-12a Standard Guide for Laboratory Immersion Corrosion Testing of Metals. West Conshohocken, PA; ASTM International. doi: https://doi.org/10.1520/NACEASTMG0031-12A

Bettman, R. B., and Zimmerman, L. M. (1935). The use of metal clips in gastrointestinal anastomosis. Am. J. Digest. Dis. 2, 318-321. doi: 10.1007/ bf03000817

Cazalbou, S., Eichert, D., Ranz, X., Drouet, C., Combes, C., Harmand, M., et al. (2005). Ion exchanges in apatites for biomedical application. J. Materials Sci.: Materials Med. 16, 405-409. doi: 10.1007/s10856-005-6979-2

De Baaij, J. H., Hoenderop, J. G., and Bindels, R. J. (2015). Magnesium in man: implications for health and disease. Physiol. Rev. 95, 1-46. doi: 10.1152/ physrev.00012.2014

Gan, J., Tan, L., Yang, K., Hu, Z., Zhang, Q., Fan, X., et al. (2013). Bioactive $\mathrm{Ca}-\mathrm{P}$ coating with self-sealing structure on pure magnesium. J. Materials Sci.: Materials Med. 24, 889-901. doi: 10.1007/s10856-0134850-4

Gusieva, K., Davies, C., Scully, J., and Birbilis, N. (2015). Corrosion of magnesium alloys: the role of alloying. Int. Materials Rev. 60, 169-194. doi: 10.1179/ $1743280414 y .0000000046$

Hargreaves, B. A., Worters, P. W., Pauly, K. B., Pauly, J. M., Koch, K. M., and Gold, G. E. (2011). Metal-induced artifacts in MRI. Am. J. Roentgenol. 197, 547-555.

\section{DATA AVAILABILITY STATEMENT}

The original contributions presented in the study are included in the article/supplementary material, further inquiries can be directed to the corresponding authors.

\section{ETHICS STATEMENT}

The animal study was reviewed and approved by the Institutional Animal Care and Use Committee of the Jeonbuk National University, Laboratory Animal Center, Jeonju-si, South Korea.

\section{AUTHOR CONTRIBUTIONS}

SW and Y-SJ conceived and designed the experiments. SW performed the experiments, analyzed the data, and drafted the manuscript. Y-SJ and M-HL revised the manuscript. All authors contributed to the article and approved the submitted version.

\section{FUNDING}

This research was supported by the Grant of the National Research Foundation of South Korea (NRF) (No. 2018R1D1A1B07049491).

Ishizaki, T., Saito, N., and Takai, O. (2010). Correlation of cell adhesive behaviors on superhydrophobic, superhydrophilic, and micropatterned superhydrophobic/superhydrophilic surfaces to their surface chemistry. Langmuir 26, 8147-8154. doi: 10.1021/la904447c

Jeong, J., Kim, J. H., Shim, J. H., Hwang, N. S., and Heo, C. Y. (2019). Bioactive calcium phosphate materials and applications in bone regeneration. Biomaterials Res. 23, 1-11.

Kim, S. M., Jo, J. H., Lee, S. M., Kang, M. H., Kim, H. E., Estrin, Y., et al. (2014). Hydroxyapatite-coated magnesium implants with improved in vitro and in vivo biocorrosion, biocompatibility, and bone response. J. Biomed. Materials Res. Part A 102, 429-441. doi: 10.1002/jbm.a.34718

Kim, S.-Y., Kim, Y.-K., Jang, Y.-S., Park, I.-S., Lee, S.-J., Jeon, J.-G., et al. (2016). Bioactive effect of alkali-heat treated TiO2 nanotubes by water or acid treatment. Surface Coatings Technol. 303, 256-267. doi: 10.1016/j.surfcoat. 2016.03.074

Lorenz, C., Brunner, J. G., Kollmannsberger, P., Jaafar, L., Fabry, B., and Virtanen, S. (2009). Effect of surface pre-treatments on biocompatibility of magnesium. Acta Biomaterialia 5, 2783-2789. doi: 10.1016/j.actbio.2009.04.018

Mekayarajjananonth, T., and Winkler, S. (1999). Contact angle measurement on dental implant biomaterials. J. Oral Implantol. 25, 230-236. doi: 10.1563/15481336(1999)025<0230:camodi> 2.3.co;2

Miura, K., Matsui, K., Kawai, T., Kato, Y., Matsui, A., Suzuki, O., et al. (2012). Octacalcium phosphate collagen composites with titanium mesh facilitate alveolar augmentation in canine mandibular bone defects. Int. J. Oral Maxillofacial Surg. 41, 1161-1169. doi: 10.1016/j.ijom.2012.05.020

Nguyen, T.-D. T., Park, I.-S., Lee, M.-H., and Bae, T.-S. (2013). Enhanced biocompatibility of a pre-calcified nanotubular $\mathrm{TiO} 2$ layer on $\mathrm{Ti}-6 \mathrm{Al}-7 \mathrm{Nb}$ alloy. Surface Coatings Technol. 236, 127-134. doi: 10.1016/j.surfcoat.2013. 09.038

Paital, S. R., and Dahotre, N. B. (2009). Calcium phosphate coatings for bio-implant applications: materials, performance factors, and methodologies. Materials Sci. Eng.: R: Rep. 66, 1-70. doi: 10.1016/j.mser.2009.05.001

Rakhmatia, Y. D., Ayukawa, Y., Furuhashi, A., and Koyano, K. (2013). Current barrier membranes: titanium mesh and other membranes for guided bone 
regeneration in dental applications. J. Prosthodontic Res. 57, 3-14. doi: 10.1016/ j.jpor.2012.12.001

Schlingmann, K. P. (2007). "Calcium-sensing receptor and magnesium," in New Perspect in Magnesium Research, eds J. Durlach, Y. Nishizawa, and H. Morii (Berlin: Springer), 272-285. doi: 10.1007/978-1-84628-483-0_22

Serre, C., Papillard, M., Chavassieux, P., Voegel, J., and Boivin, G. (1998). Influence of magnesium substitution on a collagen-apatite biomaterial on the production of a calcifying matrix by human osteoblasts. J. Biomed. Materials Res. 42, 626-633. doi: 10.1002/(sici)1097-4636(19981215)42:4<626::aid-jbm20> 3.0.co; 2 -s

Song, G. (2007). Control of biodegradation of biocompatable magnesium alloys. Corrosion Sci. 49, 1696-1701. doi: 10.1016/j.corsci.2007.01.001

Staiger, M. P., Pietak, A. M., Huadmai, J., and Dias, G. (2006). Magnesium and its alloys as orthopedic biomaterials: a review. Biomaterials 27, 1728-1734. doi: 10.1016/j.biomaterials.2005.10.003

Surmenev, R. A., Surmeneva, M. A., and Ivanova, A. A. (2014). Significance of calcium phosphate coatings for the enhancement of new bone osteogenesis-a review. Acta Biomaterialia 10, 557-579. doi: 10.1016/j.actbio.2013.10.036

Tanahashi, M., and Matsuda, T. (1997). Surface functional group dependence on apatite formation on self-assembled monolayers in a simulated body fluid. J. Biomed. Materials Res. 34, 305-315. doi: 10.1002/(sici)1097-4636(19970305) 34:3<305::aid-jbm5>3.0.co;2-o

Tian, P., and Liu, X. (2015). Surface modification of biodegradable magnesium and its alloys for biomedical applications. Regenerative Biomaterials 2, 135-151.

Walker, J., Shadanbaz, S., Woodfield, T. B., Staiger, M. P., and Dias, G. J. (2014). Magnesium biomaterials for orthopedic application: a review from a biological perspective. J. Biomed. Materials Res. Part B: Appl. Biomaterials 102, 1316-1331. doi: 10.1002/jbm.b.33113

Watanabe, H., Saito, K., Kokubun, K., Sasaki, H., and Yoshinari, M. (2012). Change in surface properties of zirconia and initial attachment of osteoblastlike cells with hydrophilic treatment. Dental Materials J. 31, 806-814. doi: 10.4012/dmj. 2012-069
Witte, F. (2010). The history of biodegradable magnesium implants: a review. Acta Biomaterialia 6, 1680-1692. doi: 10.1016/j.actbio.2010.02.028

Wong, H. M., Yeung, K. W., Lam, K. O., Tam, V., Chu, P. K., Luk, K. D., et al. (2010). A biodegradable polymer-based coating to control the performance of magnesium alloy orthopaedic implants. Biomaterials 31, 2084-2096. doi: 10.1016/j.biomaterials.2009.11.111

Wu, S., Jang, Y.-S., Kim, Y.-K., Kim, S.-Y., Ko, S.-O., and Lee, M.-H. (2019). Surface modification of pure magnesium mesh for guided bone regeneration: in vivo evaluation of rat calvarial defect. Materials Design 12:2684. doi: 10.3390/ ma12172684

Xu, L.-P., Zhang, E.-L., and Ke, Y. (2012). Biocorrosion property and cytocompatibility of calcium phosphate coated $\mathrm{Mg}$ alloy. Trans. Nonferrous Metals Soc. China 22, 2014-2020. doi: 10.1016/s1003-6326(11)614 22-2

Yang, Y., Kim, K.-H., and Ong, J. L. (2005). A review on calcium phosphate coatings produced using a sputtering process - an alternative to plasma spraying. Biomaterials 26, 327-337. doi: 10.1016/j.biomaterials.2004.02.029

Zhang, Y., Zhang, G., and Wei, M. (2009). Controlling the biodegradation rate of magnesium using biomimetic apatite coating. J. Biomed. Materials Res. Part B: Appl. Biomaterials 89, 408-414. doi: 10.1002/jbm.b.31228

Conflict of Interest: The authors declare that the research was conducted in the absence of any commercial or financial relationships that could be construed as a potential conflict of interest.

Copyright (c) $2021 \mathrm{Wu}$, Jang and Lee. This is an open-access article distributed under the terms of the Creative Commons Attribution License (CC BY). The use, distribution or reproduction in other forums is permitted, provided the original author(s) and the copyright owner(s) are credited and that the original publication in this journal is cited, in accordance with accepted academic practice. No use, distribution or reproduction is permitted which does not comply with these terms. 